\title{
Brief cognitive screening instruments for early detection of Alzheimer's disease: a systematic review
}

\author{
Ellen Elisa De Roeck ${ }^{1,2}$, Peter Paul De Deyn ${ }^{2}$, Eva Dierckx ${ }^{1 \dagger}$ and Sebastiaan Engelborghs ${ }^{2,3^{*}+}$
}

\begin{abstract}
Objectives: The objective of this systematic review was (1) to give an overview of the available short screening instruments for the early detection of Alzheimer's disease (AD) and (2) to review the psychometric properties of these instruments.
\end{abstract}

Methods: First, a systematic search of titles and abstracts of PubMed and Web of Science was conducted between February and July 2015 and updated in April 2016 and May 2018. Only papers written in English or Dutch were considered. All full-text papers about cognitive screening instruments for the early detection of AD were included, resulting in the identification of 38 pencil and paper tests and 12 computer tests. In a second step, the psychometric quality of these instruments was evaluated. Therefore, the same databases were searched again to identify papers that described the psychometric properties of the instruments meanwhile applying diagnostic criteria for the diagnostic groups included.

Results: Out of 1454 papers, 96 clearly discussed the psychometric properties of the instruments. Eighty-nine papers discussed pencil and paper tests of which 80 were validated in a memory clinic setting. Based on the number of studies (31 articles) and the sensitivity (84\%) and specificity (74\%) values, the Montreal Cognitive Assessment (MoCA) seems to be a promising (pencil and paper) screening test for memory clinic testing as well as for population screening. Regarding computer tests, validation studies were only available for 7 out of 12 tests.

Conclusions: A large number of screening tests for AD are available. However, most tests are only validated in a memory clinic setting and description of the psychometric properties of the instruments is limited. Especially, computer tests require further research. The MoCA is a promising instrument, but the specificity to detect early AD is rather low.

Keywords: Cognitive screening, Alzheimer's disease, Mild cognitive impairment, MCl, Pencil and paper tests, Computer tests, MMSE, MoCA

\section{Background}

The aging population in Europe has been growing rapidly. According to the United Nations in $2015,17.6 \%$ of the European population was older than 65 years. This will probably increase to $23.1 \%$ in 2030 . It is therefore not surprising that more and more people (will) develop

\footnotetext{
*Correspondence: sebastiaan.engelborghs@uantwerpen.be Eva Dierckx and Sebastiaan Engelborghs are joint last authors.

${ }^{2}$ Laboratory of Neurochemistry and Behavior, Institute Born-Bunge, University of Antwerp, Antwerp, Belgium

${ }^{3}$ Department of Neurology and Center for Neurosciences, UZ Brussel and Vrije Universiteit Brussel, Brussels, Belgium

Full list of author information is available at the end of the article
}

age-related diseases such as Alzheimer's disease (AD). The process of AD pathology can be described as a continuum with a long preclinical phase without clinical symptoms, an early clinical phase in which mild clinical symptoms (mild cognitive impairment (MCI) or prodromal $\mathrm{AD}$ ) are present, and a dementia phase [1-3]. For an effective intervention (including counseling, psycho-education, cognitive training, medication), early detection of the disease is important [4]. The same holds true for clinical trials with potential disease-modifying drugs for $\mathrm{AD}$ that increasingly focus on the earliest stages of the disease.

(c) The Author(s). 2019 Open Access This article is distributed under the terms of the Creative Commons Attribution 4.0 International License (http://creativecommons.org/licenses/by/4.0/), which permits unrestricted use, distribution, and 
Cognitive screening instruments are cheap, fast, and non-invasive tools to identify adults at risk to have symptomatic AD. At present, the most used cognitive screening instrument for the detection of $\mathrm{AD}$ is the Mini-Mental State Examination (MMSE [5]). However, Mitchell concluded after a meta-analysis that the MMSE has a very limited ability to differentiate between MCI and healthy controls [6]. In agreement with Mitchell's results, some reviews $[7,8]$ suggest to replace the MMSE by more performant alternatives. There are already a wide variety of alternative screening instruments in circulation. However, it is not yet clear which tests are sensitive and specific enough to detect $\mathrm{AD}$ in an early phase. Moreover, not every test is suitable for each population. As mentioned in previous reviews, it is unlikely that there is one perfect screening instrument that can be used in every population and for all types of neurodegenerative and cerebrovascular brain diseases [9]. It is logical that the preferred characteristics for a cognitive screening test vary among settings. For example, a team of researchers that wants to exclude AD in their study or clinicians in a first aid setting probably prefer a very quick and easy-to-interpret cognitive screening test whereas in a memory clinic a somewhat longer test with the inclusion of different cognitive domains could be chosen. Therefore, there is a need for a new up-to-date overview of all currently available screening instruments and their psychometric properties for the detection of AD. This systematic review will take into account different screening settings.

\section{Method}

This review consists of two parts. First, a systematic search for relevant screening instruments was performed. Second, a search was carried out to identify the psychometric properties of these screening instruments.

\section{Search strategy to identify screening instruments}

In order to identify relevant publications about screening instruments, a systematic literature search was conducted. The following electronic databases were used: Web of Science and MEDLINE. Together, these databases provide a broad coverage of (neuro)psychological and medical journals published worldwide.

The literature search was conducted in February and March 2015, updated in April 2016 and May 2018. Combinations of the search terms "cognitive screen"" and "mild cognitive impairment" and/or "Alzheimer" were used. In addition, the search terms "screen" and "computer" in combination with "mild cognitive impairment" and/or "Alzheimer" was used to identify computer screening instruments. We limited the search to studies published after 1991 in English or Dutch. Additionally, the bibliographies of published studies, particularly previous systematic reviews, were also used to search for potentially relevant screening instruments.

After reviewing the references, we selected the studies that described screening instruments with the following characteristics: (a) the test was designed to screen for cognitive impairment or could be used for that purpose, (b) the duration of the test was 20 min or less, (c) the test was available in English or Dutch, (d) the test was administered directly to patients (no informant-rated tests were used), (e) the test was not a telephone test, (f) the test was not a self-administration test, and (g) specifically for computer tests, an administrator was physically available (so no internet-based tools were included). The search resulted in 559 hits, 371 from the initial search, 127 from the first update, and 61 from the second. Thereof, 123 studies were selected that dealt with 38 different pencil and paper tests and 12 computer tests (Fig. 1). When all eligible studies about the screening instruments were identified, the relevant test variables and characteristics were extracted from the studies and summarized in a table (Tables 1, 2, and 3) (Additional file 1).

\section{Search strategy to identify the psychometric properties of the screening instruments}

Between March and July 2015 and during an update in April 2016 and May 2018, the same databases were searched again combining the names of each screening instrument with the search terms "Mild Cognitive Impairment" and/or "*Alzheimer". Once more, the search was limited to papers published after 1991 and written in English or Dutch, and bibliographies of published papers were studied to identify additional relevant articles. After reviewing the individual papers, studies for data extraction and analysis were selected based on the following criteria: (a) the paper provided basic information about sample selection and demographics, (b) the diagnostic criteria for $\mathrm{MCI}$ and/or AD were clearly described and met the standard diagnostic criteria [1, 10-12], (c) the instrument was used to detect MCI or AD dementia, and (d) the psychometric properties (sensitivity (sn), specificity (sp), reliability) of the instrument were clearly reported. The initial search and the updates resulted in 1454 references respectively, of which 89 articles about pencil and paper tests and 7 about computer tests were selected for data subtraction (Fig. 2).

First, the studies for each instrument were categorized based on the target population that was used for the validation (memory clinic versus population-based). As a screening instrument developed and validated in a (memory) clinic setting is not always appropriate to use for population screening, a distinction was made between studies validated in the general population and those validated in a (memory) clinic setting. Second, data were separately gathered for the following 


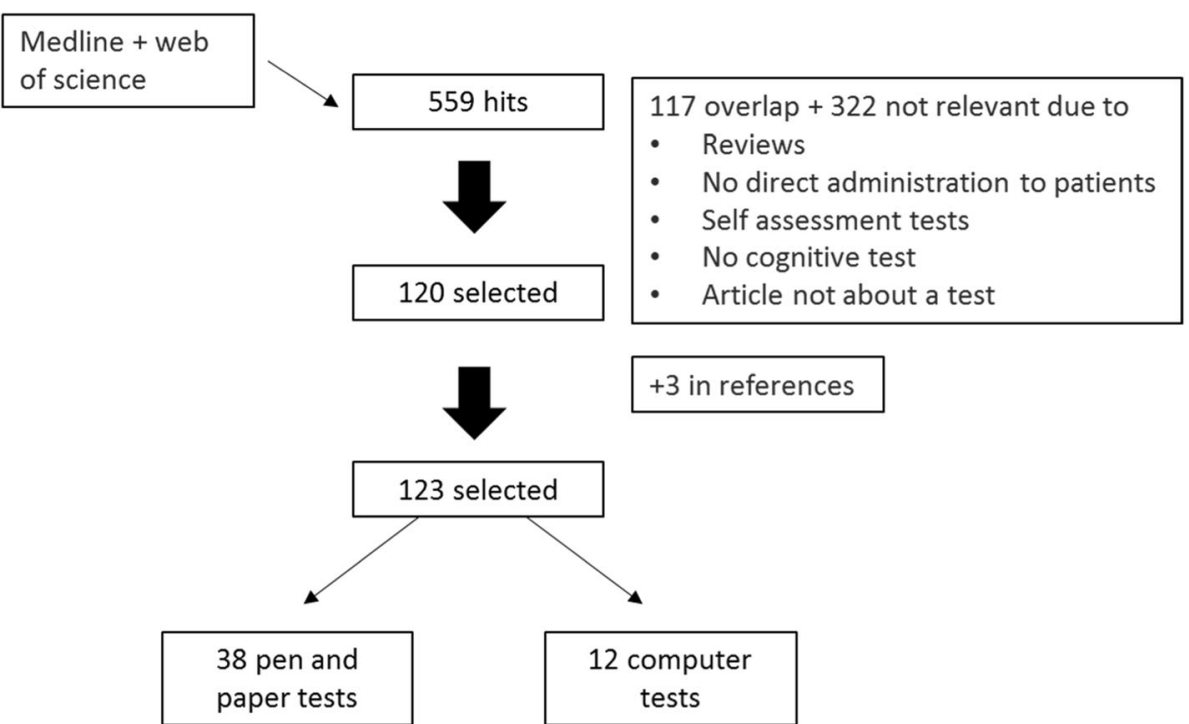

Fig. 1 Search strategy to identify screening instruments

conditions: $\mathrm{MCI}$ versus healthy controls and early $\mathrm{AD}$ dementia versus healthy controls. Third, to compare the different instruments for each condition, a weighted average for sn, sp, area under the curve (AUC), test-retest reliability, inter-rater reliability, and internal reliability was calculated, based on population sizes $(n)$.

\section{Results}

\section{Available screening instruments}

Tables 1, 2, and 3 show the details and characteristics of the 38 pencil and paper tests considered for further evaluation. In general, the tests can be divided in two groups. The first group contains 12 instruments that require $5 \mathrm{~min}$ or less to complete. Of these 12 instruments, four measure only one cognitive domain, while four instruments measure two cognitive domains and another four instruments measure three different cognitive domains. The Scenery Picture Memory Test (SPMT) and Memory Impairment Screen (MIS) only measure episodic memory. The Alzheimer Quick Test (AQT) only measures attention. Eight of these instruments include a memory task. As memory function is one of the first domains affected by AD pathology [13, 14], it could be seen as a limitation for $\mathrm{AD}$ screening that the clock drawing test (CDT), Alzheimer Quick Test (AQT), and Quick Mild Cognitive Impairment screen (Qmci) do not measure memory functioning.

Table 1 Overview of the available pencil and paper tests (part 1: short screening instruments)

\begin{tabular}{|c|c|c|c|c|c|c|c|c|c|}
\hline \multicolumn{10}{|c|}{ Tests between 2 and $5 \mathrm{~min}$} \\
\hline Abbreviation & Free?* $^{*}$ & Duration in minutes & Memory & Language & Orientation & Executive functions & Praxis & Visuospatial abilities & $\overline{\text { Attention }}$ \\
\hline CDT [15] & Yes & 2 & & & & $\mathrm{v}$ & & $\mathrm{v}$ & \\
\hline AQT [24] & No & $3-5$ & & & & & & & $v$ \\
\hline Qmci [25] & Yes & $3-5$ & & & $v$ & $v$ & & $v$ & \\
\hline Mini-Cog [26] & Yes & $2-4$ & $v$ & & & & & $v$ & \\
\hline Phototest [27] & Yes & 3 & $v$ & $v$ & & & & & \\
\hline SPMT [28] & $?$ & $2-4$ & $v$ & & & & & & \\
\hline MIS [29] & Yes & 4 & $v$ & & & & & & \\
\hline RCS [30] & Yes & $<3$ & $v$ & & & $v$ & & $\vee$ & \\
\hline 6 CIT [31] & $?$ & $2-3$ & $v$ & & $v$ & & & & $\vee$ \\
\hline SIS [32] & Yes & $2-5$ & $v$ & & $v$ & & & & \\
\hline $10-C S[33]$ & Yes & 3 & $v$ & $v$ & $v$ & & & & \\
\hline K-D test [34] & No & $1-2$ & & & & & & & $v$ \\
\hline
\end{tabular}

*Free of charge 
Table 2 Overview of the available pencil and paper tests (part 2: longer screening instruments)

\begin{tabular}{|c|c|c|c|c|c|c|c|c|c|}
\hline \multicolumn{10}{|c|}{ Tests between 5 and $20 \mathrm{~min}$} \\
\hline Abbreviation & Free?* & Duration in minutes & Memory & Language & Orientation & Executive functions & Praxis & Visuospatial abilities & Attention \\
\hline MMSE [5] & No & $5-10$ & $\mathrm{v}$ & $\mathrm{v}$ & $\mathrm{v}$ & & $\mathrm{v}$ & $\mathrm{v}$ & $\mathrm{v}$ \\
\hline 7 MS [35] & No & $7-15$ & $v$ & & v & $\vee$ & & & \\
\hline ACE-R [36] & Yes & $12-20$ & $v$ & $v$ & v & & & v & $v$ \\
\hline ACE-III [37] & Yes & & $v$ & $v$ & & & & v & $v$ \\
\hline M-ACE [38] & Yes & $<$ ACE-R & $v$ & $v$ & v & $v$ & & v & \\
\hline BCAT [39] & No & $10-15$ & $v$ & $v$ & v & $v$ & & v & $\vee$ \\
\hline Brief KSCAr [40] & Yes & 15 & $v$ & & v & $v$ & & v & $v$ \\
\hline Mini-KSCAr [41] & Yes & 10 & $v$ & & v & $v$ & & v & \\
\hline COST [42] & Yes & $5-10$ & v & v & v & v & $v$ & v & $v$ \\
\hline CONCOG [43] & Yes & $5-10$ & $v$ & $v$ & $v$ & $v$ & & v & \\
\hline DemTect [44] & Yes & $8-10$ & $v$ & $v$ & & & & & $\vee$ \\
\hline Eurotest [45] & Yes & $8-9$ & v & $v$ & & & & & $\vee$ \\
\hline FOME [46] & No & 15 & v & & & & & & \\
\hline
\end{tabular}

*Free of charge

The second group contains 26 tests that require an administration time between 5 and $21 \mathrm{~min}$. All 26 tests measure memory functions. The Fuld Object-Memory Evaluation (FOME) and the Loewenstein-Acevedo Scale for Semantic Interference and Learning (LASSI-L) only measure memory function. All other 24 instruments measure in addition to memory functions one or more other domains. The Cognitive State Test (COST), the Montreal Cognitive Assessment (MoCA), and the MoCA-basic (MoCA-B) cover all seven cognitive domains described in Tables 1, 2, and 3, namely, memory, language, orientation, executive function, praxis, visuospatial abilities, and attention. The Mini-Mental State Examination (MMSE), the Brief Cognitive Assessment Tool (BCAT), and a Short Test of Mental Status (STMS) measure six of these cognitive domains. Eight of the 24 instruments measure five cognitive domains, four instruments measure four domains, three measure three domains, and only the Short Cognitive Performance Test (SKT) measures two domains. As mentioned above, the FOME is the only instrument that measures one domain.

Table 4 provides an overview of the 12 computer tests that were included in this study. Only one computer test (Inoue) requires less than 5 min to complete, while all other tests require above $7 \mathrm{~min}$. All tests measure memory functioning, and except for the CANTAB-PAL and CANTAB mobile, they all measure multiple additional domains.

Table 3 Overview of the available pencil and paper tests (part 3: longer screening instruments)

\begin{tabular}{|c|c|c|c|c|c|c|c|c|c|}
\hline Abbreviation & Free?* $^{*}$ & Duration in minutes & Memory & Language & Orientation & Executive functions & Praxis & Visuospatial abilities & Attention \\
\hline MES [23] & Yes & 7 & $v$ & & & $\mathrm{v}$ & & & \\
\hline MoCA [47] & Yes & $10-15$ & $v$ & v & $v$ & v & $v$ & v & $v$ \\
\hline MoCA-B [19] & Yes & $15-21$ & v & v & v & v & v & v & v \\
\hline SF-MoCA [48] & Yes & $<$ MoCA & v & & $v$ & & & & v \\
\hline NUCOG [49] & No & 15 & $v$ & $v$ & & $v$ & & $v$ & $v$ \\
\hline R-QCST [50] & Yes & $10-15$ & $v$ & v & & $v$ & & v & $v$ \\
\hline RUDAS [51] & No & 20 & v & v & & v & v & v & \\
\hline SCEB [52] & $?$ & $6-12$ & $v$ & v & $v$ & v & & v & \\
\hline SKT [53] & Yes & $10-15$ & $v$ & & & & & & $v$ \\
\hline SLUMS [54] & Yes & $10-15$ & $v$ & & $v$ & $v$ & & & $v$ \\
\hline STMS [55] & Yes & $5-10$ & v & & $v$ & v & v & v & v \\
\hline TE4D-cog [56] & Yes & 10 & v & v & v & & & & v \\
\hline LaSSI-L [57] & $?$ & 20 & v & & & & & & \\
\hline
\end{tabular}




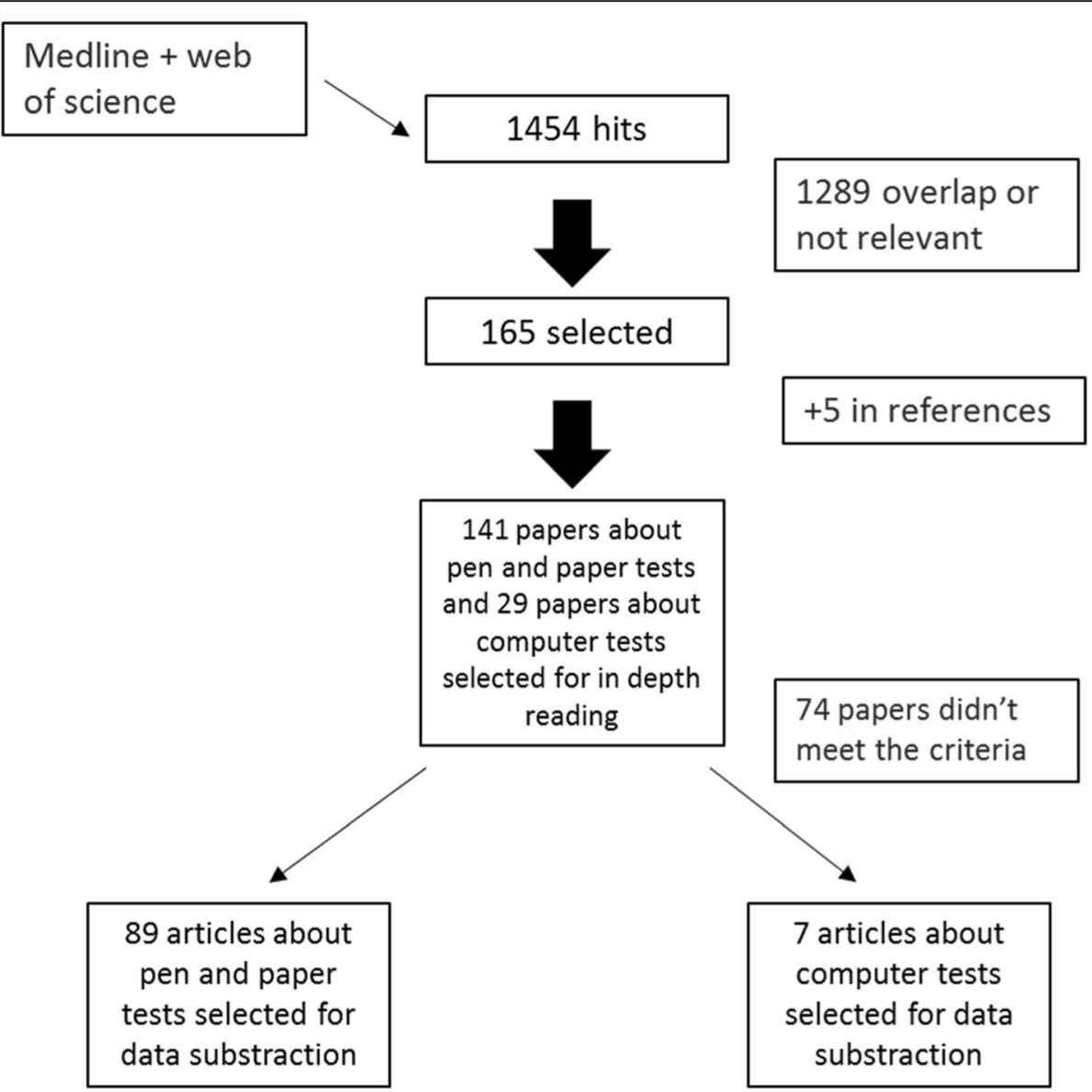

Fig. 2 Search strategy for the identification of the psychometric properties of the screening instruments

\section{Psychometric properties of the screening instruments} For further evaluation, two tests were excluded. The first was the CDT, because it is part of several other tests such as the MoCA and it has no uniform scoring system. Moreover, Ehreke and colleagues concluded in their systematic review that due to its poor psychometric properties, the CDT should not be used for MCI screening [15]. We also excluded the CDT as a screen for AD as different scoring systems for the CDT make it difficult to compare different studies that used the CDT as a

Table 4 Overview of the available computer tests

\begin{tabular}{|c|c|c|c|c|c|c|c|c|c|}
\hline Abbreviation & Free?* $^{*}$ & Duration in minutes & Memory & Language & Orientation & Executive functions & Praxis & Visuospatial abilities & Attention \\
\hline Cogstate Brief Battery [58] & Yes & $12-15$ & $v$ & & & $v$ & & & $\mathrm{v}$ \\
\hline CANTAB mobile [59] & No & 10 & $v$ & & & & & & \\
\hline CANTAB-PAL [60] & No & $8-10$ & $v$ & & & & & & \\
\hline $\mathrm{MCl}$ screen [61] & No & 10 & $v$ & $v$ & & $v$ & & & \\
\hline CANS-MCI [62] & No & $15-30$ & $v$ & $v$ & & 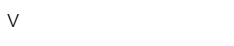 & & & \\
\hline CAMCI [63] & No & $20-25$ & $v$ & & & $v$ & & & v \\
\hline DETECT [64] & $?$ & $7-10$ & $v$ & & & $v$ & & & v \\
\hline Computer test Kluger [65] & $?$ & $12-15$ & $v$ & & 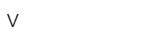 & 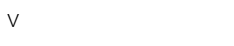 & v & & \\
\hline CST/COGselftest [66] & $?$ & 15 & $v$ & & $\vee$ & $\vee$ & & $\vee$ & v \\
\hline Computer test Inoue [67] & $?$ & 4 & v & & $v$ & & & v & \\
\hline NCGG-FAT [68] & $?$ & $20-30$ & v & & & $v$ & & v & $\vee$ \\
\hline MoCA computer tool [69] & Yes & $10-15$ & $v$ & $v$ & $v$ & $v$ & & V & v \\
\hline
\end{tabular}

*Free of charge 
screen for AD. The second excluded test was the MMSE, because it has already been reviewed extensively by Mitchell who concluded that the MMSE is not appropriate to detect mild cognitive impairment [6].

\section{Pencil and paper test: detection of mild cognitive impairment}

Tables 5 and 6 summarize the different instruments and their psychometric properties validated in a (memory) clinic setting. From the 12 short-duration instruments, only seven were validated in a (memory) clinic setting for MCI. For five of these six instruments, there is only one study published; for the phototest and Qmci, there are two different studies published. Both the six-item screener (SIS) and the 10-point cognitive screener (10-CS) present with high sp for MCI but low sn. Based on sn, sp, and AUC, the Qmci and phototest score well, whereby the Qmci results might be more valid as it has been tested in more participants.

For 18 of the 26 long-duration screening instruments, psychometric properties to screen for MCI are available. The MoCA is the best studied instrument, as it is covered in 20 papers, followed by the Addenbrooke's Cognitive Examination Revised (ACE-R), described in seven studies. For both the ACE-R and the MoCA, sn is high (>80\%) while sp is rather low (respectively $74.6 \%$ and $77.4 \%$ ). Based on the combination of sn (>80\%), sp (>80\%), and AUC (>90\%), the SKT, DEMTECT, Memory and Executive Screening (MES), Quick Cognitive Screening Test (QCST), and MoCA-Basic (MoCA-B) are promising tests to screen for $\mathrm{MCI}$ in a memory clinic. However, more studies are needed to confirm these results.

As shown in Table 7, only two instruments are validated in a population-based cohort, namely the MoCA and BCAT. Again the MoCA is with six studies the best studied instrument. For both tests, the psychometric properties are reasonable (sn and $\mathrm{sp}>80 \%$ ).

\section{Pencil and paper tests: detection of Alzheimer's disease}

The variables in Tables 8 and 9 are the same as those in Tables 5 and 6 , but the instruments and their psychometric properties are validated in AD dementia instead of MCI. From the initial 11 short-duration instruments that were found, only six were validated for $\mathrm{AD}$ in a (memory) clinic setting. If we compare sn, sp, and AUC of the instruments with those of the validation in MCI (Tables 5 and 6), the values are higher. Based on the three statistical measures, the phototest seems to be the most accurate short-duration instrument, followed by the AQT and SPMT. The test-retest results of the AQT, MIS, and SPMT are good. The only instrument of which the inter-rater reliability was described is the SPMT, with good reliability. For the Mini-Cog, only results about sn were available.

Seventeen out of the 26 long-duration screening instruments are validated for AD. Again, the best studied instrument, described in 13 papers, was the MoCA, followed by the ACE-R and $7 \mathrm{MS}$, both described in four studies. The sn, sp, and AUC of both the MoCA and the MES were good (>90\%), making these the two superior tests. However, the psychometric properties of the other tests were, except for the SKT, all reasonable (>74\%). The sp of the SKT was inadequate (51.9\%).

Table 10 demonstrates again that only a few screening instruments are validated in a population-based cohort. For the MoCA, two studies are available, while for the MIS, only one study is published. The sn of the MoCA is high $(96.6 \%)$ with a reasonable sp $(81.8 \%)$. The psychometric properties for the MIS, a very short instrument, are also good (all > 85\%).

\section{Computer tests}

Table 11 gives an overview of the computer instruments that are validated in a clinic setting. The first part is the results for the instruments that are validated for $\mathrm{MCI}$, and the second part contains the results for $\mathrm{AD}$. As can be seen in the tables, most studies are underpowered as

Table 5 Overview of the psychometric properties for pencil and paper tests validated in a (memory) clinic for $\mathrm{MCl}$ (part 1: short screening instruments)

\begin{tabular}{|c|c|c|c|c|c|c|c|c|c|c|c|c|c|}
\hline Instrument & $\begin{array}{l}\text { Number } \\
\text { of articles* }\end{array}$ & $\begin{array}{l}N \text { healthy } \\
\text { controls }\end{array}$ & $\begin{array}{l}\mathrm{N} \\
\mathrm{MCl}\end{array}$ & $n$ & Sensitivity & Specificity & $n$ & AUC $n$ & $\begin{array}{l}\text { Internal } \\
\text { consistency }\end{array}$ & $n$ & $\begin{array}{l}\text { Inter-rater } \\
\text { reliability }\end{array}$ & $n$ & $\begin{array}{l}\text { Test-retest reliability } \\
\text { (mean time between tests) }\end{array}$ \\
\hline Phototest & 2 & 85 & 98 & 183 & 77.1 & 91.5 & 91 & 93 & & & & & \\
\hline Qmci & 3 & 851 & 305 & 1416 & 85.7 & 85.7 & 307 & 92.3 & & & & 30 & 0.93 (31.1 days) \\
\hline AQT & 1 & 47 & 75 & 122 & 80 & 76 & 122 & 85 & & & & 122 & 0.88 (16 weeks) \\
\hline SIS & 1 & 375 & 440 & 815 & 34.3 & 90.1 & 815 & 63.2 & & & & & \\
\hline $6 \mathrm{CIT}$ & 1 & 130 & 67 & 197 & 66 & 70 & 197 & 71 & & & & & \\
\hline $10-\mathrm{CS}$ & 1 & 106 & 56 & 162 & 60.5 & 94.3 & 162 & 85 & & & & & \\
\hline K-D test & 1 & 135 & 39 & 174 & 92.3 & & 174 & 71 & & & & & \\
\hline
\end{tabular}

*When more than 1 study is available, the weighted mean is calculated for the sensitivity, specificity, AUC, internal consistency, inter-rater reliability, and test-retest reliability 
Table 6 Overview of the psychometric properties for pencil and paper tests validated in a (memory) clinic for $\mathrm{MCl}$ (part 2: longer screening instruments)

\begin{tabular}{|c|c|c|c|c|c|c|c|c|c|c|c|c|c|c|}
\hline Instrument & $\begin{array}{l}\text { Number } \\
\text { of articles* }\end{array}$ & $\begin{array}{l}N \\
\text { healthy } \\
\text { controls }\end{array}$ & $\begin{array}{l}\mathrm{N} \\
\mathrm{MCl}\end{array}$ & $n$ & Sensitivity & Specificity & $n$ & $A \cup C$ & $n$ & $\begin{array}{l}\text { Internal } \\
\text { consistency }\end{array}$ & $n$ & $\begin{array}{l}\text { Inter-rater } \\
\text { reliability }\end{array}$ & $n$ & $\begin{array}{l}\text { Test-retest reliability } \\
\text { (mean time between } \\
\text { tests) }\end{array}$ \\
\hline NUCOG & 1 & 60 & 8 & 68 & 83.3 & 87.5 & & & 68 & 0.92 & & & & \\
\hline MoCA & 20 & 1628 & 1149 & 2777 & 83.9 & 74.6 & 2179 & 85.1 & 1801 & 0.78 & 724 & 0.97 & 1189 & 0.88 (3-24 weeks) \\
\hline MoCA-B & 1 & 43 & 42 & 85 & 81 & 86 & 85 & 90 & 85 & 0.82 & & & 25 & 0.91 (2 months) \\
\hline SF-MoCA & 1 & 28 & 43 & 71 & & & 71 & 86 & & & & & & \\
\hline ACE-M & 1 & 72 & 39 & 111 & 77 & 82 & & & & & & & & \\
\hline ACE-R & 7 & 334 & 276 & 610 & 82.8 & 77.4 & 546 & 87.1 & 528 & 0.87 & 522 & 0.94 & 430 & 0.95 (4-6 weeks) \\
\hline Mini-KSCAr & 1 & 21 & 27 & 48 & 81 & 95 & & & & & & & & \\
\hline FBMS & 1 & 80 & 23 & 103 & 82.6 & 87.5 & & & & & & & 103 & 0.65 (9 weeks) \\
\hline SLUMS & 2 & 491 & 237 & 1112 & 84.5 & 75.3 & 728 & 90.5 & 274 & 0.85 & & & & \\
\hline SKT & 1 & 56 & 82 & 138 & 100 & 84.8 & 138 & 99.1 & 138 & 0.8 & & & & \\
\hline QCST & 1 & 186 & 121 & 307 & 87.6 & 83.3 & 307 & 92.3 & & & & & 307 & 0.93 (32.1 days) \\
\hline DemTect & 3 & 182 & 195 & 516 & 84.1 & 91.5 & 153 & 96.8 & & & 242 & 0.99 & & \\
\hline SCEB & 1 & 48 & 27 & 75 & 75 & 86 & 75 & 86 & & & & & & \\
\hline STMS & 2 & 839 & 261 & 1100 & 68 & 76 & 1100 & 81.6 & & & & & & \\
\hline MES & 1 & 197 & 310 & 507 & 83.7 & 87.1 & 507 & 92.2 & & & 507 & 0.92 & & \\
\hline RUDAS & 2 & 228 & 82 & 88 & 56.8 & 90.3 & 228 & 79.7 & 77 & 0.71 & 77 & 0.88 & 77 & 0.90 (4 weeks) \\
\hline RCS & 1 & 33 & 61 & 94 & 87 & 70 & & & & & & & & \\
\hline LASSI-L & 1 & 44 & 15 & 59 & 73,3 & 93.2 & & & & & & & & \\
\hline
\end{tabular}

*When more than 1 study is available, the weighted mean is calculated for the sensitivity, specificity, AUC, internal consistency, inter-rater reliability, and test-retest reliability

very few participants are included in the validation studies. Together, the studies evaluating the Cogstate include most participants. For the detection of MCI, the Cogstate and MoCA-CC have good psychometric properties. For the detection of $\mathrm{AD}$, the CANS-MCI and Cogstate are preferred.

There is only one computer test validated in a population-based cohort, namely the Computer Assessment of Mild Cognitive Impairment (CAMCI) with a sn of $86 \%$ and a sp of $94 \%$.

\section{Discussion}

The aims of this review were to identify and evaluate available screening instruments for early detection of $\mathrm{AD}$ and $\mathrm{MCI}$. As mentioned in the introduction, not for every setting the same tests are appropriate. Therefore, we will discuss briefly two general findings and subsequently discuss the applicability of the different cognitive screens in different settings.

\section{General findings}

A first general finding is that a large number of screening instruments are available. However, for 10 out of the 38 instruments, no paper was found that clearly described the validation in $\mathrm{MCI}$ or $\mathrm{AD}$. In addition, most instruments had only one paper dedicated to their validation. Besides, as Tables 5, 6, 7, 8, 9, and 10 show, only a limited amount of researchers reported reliability statistics for their instruments. Adequate reliability is essential for robust validity and should therefore be evaluated when validating an instrument. Another remark is the small sample sizes of some studies. Such underpowered studies may lead to misrepresenting results. In order to get representative results, studies with more participants are needed.

Table 7 Overview of the psychometric properties for pencil and paper tests validated in a population-based cohort for $\mathrm{MCl}$

\begin{tabular}{|c|c|c|c|c|c|c|c|c|c|c|c|c|c|}
\hline Instrument & $\begin{array}{l}\text { Number } \\
\text { of articles* }\end{array}$ & $\begin{array}{l}N \\
\text { healthy } \\
\text { controls }\end{array}$ & $\begin{array}{l}N \\
\mathrm{MCl}\end{array}$ & $n$ & Sensitivity & Specificity & $n$ & AUC & $n$ & $\begin{array}{l}\text { Internal } \\
\text { consistency }\end{array}$ & $\begin{array}{ll}n & \text { Inter-rater } \\
& \text { reliability }\end{array}$ & $n$ & $\begin{array}{l}\text { Test-retest reliability } \\
\text { (mean time } \\
\text { between tests) }\end{array}$ \\
\hline$\overline{\text { BCAT }}$ & 1 & 49 & 26 & 75 & 81 & 80 & 75 & 90 & & & & & \\
\hline MoCA & 7 & 11,738 & 4365 & 16,103 & 82.6 & 85.6 & 15,919 & 89.1 & 15,595 & 0.89 & & 840 & 0.92 (6-35 days) \\
\hline
\end{tabular}

*When more than 1 study is available, the weighted mean is calculated for the sensitivity, specificity, AUC, internal consistency, inter-rater reliability, and test-retest reliability 
Table 8 Overview of the psychometric properties for pencil and paper tests validated in a (memory) clinic for AD dementia (part 1)

\begin{tabular}{|c|c|c|c|c|c|c|c|c|c|c|c|c|c|}
\hline Name & $\begin{array}{l}\text { Number of } \\
\text { articles }\end{array}$ & $\begin{array}{l}\text { Healthy } \\
\text { controls }\end{array}$ & $A D$ & $n$ & Sensitivity & Specificity & $n$ & $A \cup C$ & $\begin{array}{ll}n & \text { Internal } \\
& \text { consistency }\end{array}$ & $n$ & Inter-rater & $n$ & $\begin{array}{l}\text { Test-retest } \\
\text { (mean time between tests) }\end{array}$ \\
\hline$\overline{\mathrm{AQT}}$ & 1 & 47 & 180 & 227 & 88 & 82 & 227 & 95 & & & & 227 & 0.88 (16 weeks) \\
\hline MIS & 1 & 206 & 187 & 393 & 97 & & & & & & & 187 & $0.91(?)$ \\
\hline SIS & 1 & 475 & 1061 & 1536 & 88.5 & 78.3 & 1536 & 83.8 & & & & & \\
\hline Phototest & 1 & 30 & 56 & 86 & 89.3 & 96.7 & 86 & 97 & & & & & \\
\hline SPMT & 1 & 54 & 128 & 182 & 84.8 & 89.8 & 182 & 92.5 & & 128 & $0.750^{*} 0.795^{* *}$ & 128 & $\begin{array}{l}0.898^{*} \\
0.929^{* *} \text { (2.3 months) }\end{array}$ \\
\hline Mini-Cog & 1 & 64 & 215 & 279 & 90.7 & & & & & & & & \\
\hline K-D test & 1 & 135 & 32 & 167 & 93.8 & & 167 & 74 & & & & & \\
\hline
\end{tabular}

*Pic $1,{ }^{* *}$ pic 2

A second general finding is the paucity of studies describing the validation of computer instruments. Next to that, none of the reviewed computer instruments showed compelling evidence of superiority above pencil and paper tests despite some advantages of computerized tests, such as exact recording, highly standardized format, the possibility to adapt instructions or tasks to the abilities of the participants to avoid floor and ceiling effects and the convenience of automatic calculation of scores. The lack of studies describing the validation of computer instruments may be partly due to the negative association between older adults and computers. Indeed, a majority of older adults lack familiarity with computers, which can negatively affect performance $[16,17]$. For example, according to a study of Perla and colleagues, participants that were unfamiliar with computers, female participants, and participants with a lower socioeconomic status were less inclined to do a computer screening for dementia [18]. Another explanation could be that we restricted our search to instruments that need an administrator, so web-based screening tools that can be administered on the home computer without the presence of a specialized administrator were excluded.

\section{Population screening}

Population-based validation of screening tests is important, as it may (a) result in norms which can serve as reference values to evaluate how well an individual performs compared with the general population and (b)

Table 9 Overview of the psychometric properties for pencil and paper tests validated in a (memory) clinic for AD dementia (part 2)

\begin{tabular}{|c|c|c|c|c|c|c|c|c|c|c|c|c|c|c|}
\hline Name & $\begin{array}{l}\text { Number of } \\
\text { articles* }\end{array}$ & $\begin{array}{l}\text { Healthy } \\
\text { controls }\end{array}$ & $A D$ & $n$ & Sensitivity & Specificity & $n$ & AUC & $n$ & $\begin{array}{l}\text { Internal } \\
\text { consistency }\end{array}$ & $n$ & Inter-rater & $n$ & $\begin{array}{l}\text { Test-retest (mean time } \\
\text { between tests) }\end{array}$ \\
\hline NOCUG & 1 & 60 & 17 & 77 & 100 & 100 & & & & & & & & \\
\hline MoCA & 15 & 1552 & 1290 & 2842 & 92.7 & 91.4 & 1968 & 96.7 & 1715 & 0.84 & 562 & 0.98 & 874 & $\begin{array}{l}0.86 \\
\text { (between } 1 \text { and } 3 \text { months) }\end{array}$ \\
\hline ACE-R & 4 & 299 & 254 & 553 & 96.3 & 82.7 & 477 & 98.1 & 255 & 0.89 & 255 & 1 & 45 & 0.91 (4 weeks) \\
\hline $7 \mathrm{MS}$ & 4 & 373 & 320 & 693 & 93.7 & 92.9 & 419 & 97.5 & 154 & 0.79 & 269 & 0.96 & 50 & 0.91 ( 1 to 2 months) \\
\hline $\begin{array}{l}\text { Mini- } \\
\text { KSCAr }\end{array}$ & 2 & 21 & 37 & 58 & 100 & 95 & & & & & 160 & 0.99 & & \\
\hline FBMS & 1 & 80 & 25 & 105 & 100 & 87.5 & 105 & 98.5 & & & & & 105 & 0.65 (9 weeks) \\
\hline TE4D & 1 & 25 & 178 & 203 & 100 & & & & 203 & 0.87 & 203 & 1 & & \\
\hline SKT & 1 & 56 & 46 & 102 & 85.3 & 51.9 & 102 & 75.1 & & & & & & \\
\hline RUDAS & 1 & 23 & 23 & 46 & 100 & 74 & & & & & & & & \\
\hline COST & 1 & 114 & 74 & 188 & 81 & 99 & 188 & 94 & 114 & 0.88 & & & & \\
\hline SCEB & 2 & 95 & 78 & 173 & 93.4 & 88.5 & 173 & 96.1 & & & & & & \\
\hline STMS & 1 & 788 & 235 & 1023 & & & 1023 & 97 & & & & & & \\
\hline MES & 1 & 197 & 228 & 425 & 99 & 98.8 & 425 & 99.8 & & & 228 & 0.92 & & \\
\hline Demtect & 3 & 182 & 248 & 430 & 95.8 & 86.1 & 164 & 86.2 & & & 266 & 0.99 & & \\
\hline SF-MoCA & 1 & 28 & 20 & 48 & & & 48 & 93 & & & & & & \\
\hline LASSI-L & 1 & 44 & 19 & 63 & 78.9 & 97.7 & & & & & & & & \\
\hline
\end{tabular}

*When more than 1 study is available, the weighted mean is calculated for the sensitivity, specificity, AUC, internal consistency, inter-rater reliability, and test-retest reliability 
Table 10 Overview of the psychometric properties for pencil and paper tests validated in a population-based cohort for AD

\begin{tabular}{lllllllllllll}
\hline Instrument & $\begin{array}{l}\text { Number of } \\
\text { articles* }\end{array}$ & $\begin{array}{l}N \\
\text { healthy } \\
\text { controls }\end{array}$ & AD & & & & & & & & &
\end{tabular}

*When more than 1 study is available, the weighted mean is calculated for the sensitivity, specificity, AUC, internal consistency, inter-rater reliability, and test-retest reliability

let us gain insight in normal aging. Moreover, good diagnostic instruments that can be used for population screening should be available when disease-modifying treatment options for AD become available [4]. However, the most important finding for population-based research is the lack of instruments that are validated in a population-based cohort. In this review, there is only one computer test, one short pencil and paper test, and two longer pencil and paper tests that are validated in a population-based cohort. The CAMCI is the only computer test that is validated for $\mathrm{MCI}$ in a population-based cohort. For AD, there were none. The CAMCI is an interesting instrument as its psychometric properties are good and it uses different tasks that are affected by AD, like navigation and memory.

The only short-duration instrument validated for $\mathrm{AD}$ dementia in a population-based cohort was the MIS. It showed good sn and sp to differentiate AD dementia patients from healthy controls. However, it is not validated for MCI. An explanation for the low number of short-duration instruments that was validated could be that they are often part of a broader neuropsychological examination. Therefore, they are not discussed as a screening instrument.

The psychometric properties of the MoCA, a longer duration instrument, are of all the population-based validated screens the best studied. Although the MoCA's psychometric results score good, our results are somewhat less positive than those reported in a review of Julayanont and colleagues [19]. It is important to mention that Julayanont did not differentiate between a population-based or a (memory) clinic setting. In their review, sn for MCI detection was on average $86 \%$, while the weighted average for the general population in our review is $82.6 \%$. The sn in Julayanont's review to detect AD was on average $97 \%$, while the weighted average in this review is $96.6 \%$. The sp for both $\mathrm{MCI}$ and $\mathrm{AD}$ together was on average $88 \%$. In our study, the weighted average sp for $\mathrm{MCI}$ and $\mathrm{AD}$ is respectively $85.6 \%$ and $81.8 \%$ in a population-based cohort. The lower average sn and sp can be explained by the use of weighted averages in our review and by the fact that new studies were taken into account.

Table 11 Overview of the psychometric properties for computer tests

\begin{tabular}{|c|c|c|c|c|c|c|c|c|c|c|c|c|c|}
\hline Instrument & $\begin{array}{l}\text { Number } \\
\text { of articles* }\end{array}$ & $\begin{array}{l}\text { N } \\
\text { healthy } \\
\text { controls }\end{array}$ & $\begin{array}{l}\mathrm{N} \\
\mathrm{MCl} / \mathrm{AD}\end{array}$ & $n$ & Sensitivity & Specificity & $n$ & $A \cup C$ & $n$ & $\begin{array}{l}\text { Internal } \\
\text { consistency }\end{array}$ & $\begin{array}{ll}n & \text { Inter-rater } \\
& \text { reliability }\end{array}$ & $n$ & $\begin{array}{l}\text { Test-retest reliability } \\
\text { (mean time } \\
\text { between tests) }\end{array}$ \\
\hline \multicolumn{14}{|c|}{ Test validated for $\mathrm{MCl}$ in a (memory) clinic } \\
\hline Cogstate & 1 & 653 & 107 & 760 & 80.4 & 84.7 & 760 & 91.0 & & & & & \\
\hline CANTAB-PAL & 1 & 22 & 17 & 39 & & & 39 & 80.3 & & & & & \\
\hline CANS-MCI & 2 & 61 & 50 & 111 & 83.5 & 73.0 & 111 & 82.1 & 97 & 0.77 & & 97 & $\begin{array}{l}0.88 \\
\text { (3 months) }\end{array}$ \\
\hline $\begin{array}{l}\text { MoCA computer tool } \\
\text { (MoCA-CC) }\end{array}$ & 1 & 85 & 96 & 781 & 95.8 & 87.1 & 781 & 97.0 & & & & & $\begin{array}{l}0.82 \\
\text { (6 weeks) }\end{array}$ \\
\hline \multicolumn{14}{|c|}{ Test validated for $\mathrm{MCl}$ in a population-based cohort } \\
\hline CAMCI 1 & & 296 & 228 & 524 & 86 & 94.0 & & & 524 & 0.72 & & & \\
\hline \multicolumn{14}{|c|}{ Tests validated for $A D$ in a (memory) clinic } \\
\hline Cogstate & 1 & 653 & 44 & 697 & 100.0 & 84.7 & 653 & 99.0 & & & & 697 & $\begin{array}{l}0.70 \\
\text { (4 months) }\end{array}$ \\
\hline CANTAB-PAL & 1 & 16 & 34 & 50 & 68.0 & 98.0 & & & & & & & \\
\hline CANS-MCI & 1 & 41 & 21 & 62 & 100.0 & 97.0 & 62 & 98.0 & 97 & 0.77 & & 97 & $\begin{array}{l}0.88 \\
\text { (3 months) }\end{array}$ \\
\hline Test Inoue & 1 & 102 & 72 & 174 & 96.0 & 86.0 & & & & & & & \\
\hline
\end{tabular}

*When more than 1 study is available, the weighted mean is calculated for the sensitivity, specificity, AUC, internal consistency, inter-rater reliability, and test-retest reliability 


\section{Clinical setting}

\section{The short-duration instruments $(<5 \mathrm{~min})$}

In some clinical settings (especially primary care), a short instrument is needed. This instrument's purpose is to help to select older adults in need for a more detailed cognitive evaluation. The most crucial characteristic of these instruments is a short administration time. Therefore, we will below discuss all instruments with an administration time of $5 \mathrm{~min}$ or less.

For detection of MCI, the Qmci and phototest are preferable, with the Qmci being the most studied instrument. The Qmci is a modified version of the AB Cognitive Screen 135 (ABCS 135; [20]) which emphasizes the subtest from the ABCS 135 that best discriminated MCI from healthy controls, namely delayed recall and verbal fluency. The phototest assesses visual naming, verbal fluency, and episodic memory. The phototest is developed to be used in people with low education. Of the short-duration instruments, the SIS scored the weakest. Both SIS and 10-CS had high sp for MCI but low sn, indicating that the tasks are too easy for MCI patients (ceiling effect) and a lot of them are classified as false negatives. To detect $\mathrm{AD}$, based on the statistical measures, the phototest is the best short-duration instrument, closely followed by the AQT, SPMT, and MIS. Again, the SIS scored low. Our results are somewhat in line with previous reviews. For example, Brodaty and colleagues concluded that the best very short screening instruments for a GP are the General Practitioner Assessment of Cognition (GPCOG), Mini-Cog, or the Memory Impairment Screen (MIS) [21]. Also, in a review of Lin and colleagues, the MIS was considered as a good instrument to detect cognitive impairment in older adults [22]. However, both reviews only took into account cognitive impairment in general and not specifically the early stages of impairment such as MCI due to AD.

Therefore, at this moment, we recommend to use the Qmci to detect MCI, the phototest to detect MCI in patients with low education levels, and the AQT, SPMT, or MIS to detect AD.

\section{Long-duration screening instruments}

For more specialized settings like for example a memory clinic or clinical trials, somewhat longer screening instruments are preferred. In this setting, the instruments are not solely used to screen for cognitive impairment, but can also be used for follow-up and for clinical trials to assess the patient's response to treatment. Therefore, we will below discuss the instruments with an administration time between 6 and $20 \mathrm{~min}$.

The results of our data search indicate that none of the long-duration screening instruments are suitable for detecting MCI. Especially, the balance between sp and sn forms an issue for a lot of instruments. For the
ACE-M (sn 77.0\%, sp 82.0\%), RUDAS (sn 56.8\%, sp $90.3 \%$ ), and SCEB (sn 75.0\%, sp 86.0\%), the sn is relatively low, indicating that these instruments will allocate many MCIs as healthy controls. In contrast, the sp of the MoCA (sn 83.9\%, sp 74.6\%), ACE-R (sn 82.8\%, sp 77.4\%), RCS (sn 87\%, sp 70.0\%), and SLUMS (sn 84.5\%, sp $75.3 \%$ ) is rather low. With low sp, many healthy subjects will be classified as having MCI and be referred for further examination. This may elevate health care costs and worry the participants. Of all the instruments, the NUCOG, ACE-R, mini-KSCAR, SKT, Demtect, QCST, and MoCA-B have average psychometric results. The MoCA, however, is the best studied instrument, followed by the ACR-R. An advantage of the ACE-R is the availability of differential diagnosis profiles. For each individual, a profile is constructed that indicates the likelihood that their impairment is due to $\mathrm{AD}$ versus frontotemporal dementia. At the moment, the ACE-III, a new version of the ACE-R, is on the market. However, its value and specific statistical properties are not yet studied as much as the ACE-R, so whether the new version is better than its previous cannot be determined yet. For the detection of AD dementia, the MoCA and Memory and Executive Screening (MES) test perform best. The MES test is developed by Guo and colleagues for the detection of MCI and mild AD dementia and focuses on memory and executive functioning [23].

It is worth mentioning that all long-duration screening instruments measure episodic memory. This is positive and also logical as one of the first noticeable symptoms of $\mathrm{AD}$ are problems with episodic memory. Another important finding is that the MoCA is extensively studied. Interestingly, researchers are adapting the MoCA for different populations (for example, the MoCA-B for people with low education levels) and devices (for example, the MoCA-CC for the computer).

From all the computer instruments, the MoCA-CC (all statistics above $87 \%$ ) and Cogstate (all statistics above sn, sp, and AUC $\geq 80 \%$ ) show promising psychometric properties when used to detect MCI in a (memory) clinic setting. For the detection of AD dementia, the Cogstate, CANS-MCI, and computer test of Inoue all perform well. From these three tests, CANS-MCI is specifically designed to be sensitive for MCI and AD pathology, as it focuses on the cognitive domains affected by AD.

\section{Strengths and limitations}

It should be mentioned that this review has its strengths and limitations.

A first limitation is that in our attempt to present as many instruments as possible, it was not feasible to conduct a detailed quality rating of each individual study from which we extracted the data presented in this review. However, by applying strict inclusion criteria, for 
example by excluding studies using wrong diagnostic criteria, for example identifying MCI or AD with a screening instrument, for $\mathrm{AD}, \mathrm{MCI}$, and healthy controls, this limitation was minimized as much as possible.

Another limitation is the lack of information, provided by authors of the selected studies, about the power of the instrument to differentiate between different forms of dementia. With most instruments, it is therefore not possible to differentiate between participants with probable AD or other causes of dementia such as Lewy body dementia or vascular dementia. Almost all screening instruments use a simple dichotomized cutoff (cognitively impaired or not), while it could be more interesting for clinicians to have a short instrument that distinguishes between different etiologies. However, the measurement of different cognitive domains is needed, to make differential profiles which would increase the administration time. Especially for very short instruments, the ability to differentiate between dementias may be questionable. For longer screening tests such as the ACE-R, this is already possible, but it is time-consuming for the administrator. Hence, differential diagnostic power may also be beneficial for computer instruments, particularly if the profiles are automatically calculated.

It can be seen as a shortcoming that we did not provide information about the instrument's ability to differentiate between MCI and AD dementia. However, in our opinion, the aim of a screening instrument is to identify cognitive impairment or, if screening for $\mathrm{AD}$, cognitive impairment that points in the direction of $\mathrm{AD}$ pathology. In both cases, further research is needed. In clinical practice, (instrumental) activities of daily living ((I)ADL) functioning is crucial to differentiate between the MCI and the dementia stage [1-3]. Hence, differentiating between $\mathrm{MCI}$ and $\mathrm{AD}$ with a cognitive screening instrument, without measuring (I)ADL functioning, would have little clinical benefit.

A next limitation is that we restricted our search to instruments that need an administrator and include only a measurement of the participant themselves. Due to this restriction, some promising screening instruments, such as the GPCOG, informant-rated questionnaires, or web-based screening tools, were not evaluated and discussed in this review.

A following limitation includes that we only discuss in this review a few psychometric properties. These are the psychometric properties that are most commonly described in the included studies. However, other psychometric properties such as construct and criterion or predictive validity were not discussed. A last limitation is that within this review, $\mathrm{MCI}$ is treated as one concept, despite the fact that most clinicians and researchers differentiate between different subtypes of MCI (amnestic, non-amnestic, multiple or single domain) [11]. However, the majority of the included studies grouped all MCI types as one diagnostic group or did analyses on the whole MCI group.

\section{Further research}

More instruments should be tested in population-based cohorts. In addition, the balance between sp and sn should be improved through further research. To this end, it could be helpful to take into account the pathophysiological background of AD. Within this light, it may be interesting to improve the existing instruments and potentially adapt them for several settings and populations, such as the adaptation of the MoCA for lower educated people or for people with hearing impairments $[19,22]$. Besides, the sp of the MoCA needs to be improved. Additionally, more research is needed for computer instruments, especially to adapt them for different devices (tablet, home computer), how they influence cognitive processes, and which device is most appropriate for older adults with and without computer experience. Finally, future reviews could focus on the screening ability of the instruments for the different subtypes of MCI and dementia and the ability of the instruments for other purposes such as measuring progression of cognitive decline and evaluating potential treatment effects and could include additional psychometric properties such as predictive values.

\section{Recommendations}

Clinicians and researchers should abandon the idea that one screening instrument (like the MMSE) can be used in every setting, for all different neurodegenerative diseases and for each population. Tables 5, 6, and 12 summarize our recommendations. For the detection of $\mathrm{MCI}$ and $\mathrm{AD}$ in a population-based cohort, the MoCA is the most suitable instrument. If a shorter instrument is needed, the MIS can be used to detect AD dementia. In a (memory) clinic setting, the Qmci is a suitable short-duration

Table 12 Overview of the recommended tests

\begin{tabular}{cll}
\hline & $\begin{array}{l}\text { Recommended tests } \\
\text { to detect MCI }\end{array}$ & $\begin{array}{l}\text { Recommended tests } \\
\text { to detect AD }\end{array}$ \\
\hline $\begin{array}{c}\text { Population screening } \\
\text { Longer screening }\end{array}$ & $/$ & MIS \\
(Memory) clinic setting & MoCA & MoCA \\
Short screening & $\begin{array}{l}\text { Qmci } \\
\text { Phototest } \\
\text { (lower education) }\end{array}$ & \\
& MIS \\
& MoCA/MoCA-CC & MoCA, MES \\
& ACE-R & \\
& Mini-KSCAR & \\
& NUCOG \\
& DEMTECT \\
& Cogstate & \\
\hline
\end{tabular}


screening instrument, while the phototest can be used for people with lower education levels The NUCOG, ACE-R, mini-KSCAR, SKT, Demtect, QCST, and MoCA-B are good candidates to choose from the longer screening instrument. The best studied test is the MoCA. If differential diagnosis is needed, the ACE- $\mathrm{R}$ is preferred. For the detection of $\mathrm{AD}$ dementia, the MoCA and MES can be used. For the detection of MCI and AD, the MoCA-CC and Cogstate seem promising computer instruments.

\section{Additional file}

Additional file 1: Detailed overview of the studies included in this review. (DOCX 29 kb)

\section{Abbreviations}

10-CS: 10-point cognitive screener; 6 CIT: Six-Item Cognitive Impairment Test; 7 MS: 7-min screening test; ABCS 135: AB Cognitive Screen; ACE-

III: Addenbrooke's Cognitive Examination III; ACE-R: Addenbrooke's Cognitive Examination Revised; AD: Alzheimer's disease; AQT: Alzheimer's Quick Test; BCAT: Brief Cognitive Assessment Tool; Brief KSCAr: Brief Kingston Standardized Cognitive Assessment revised; CAMCl: Computer Assessment of Mild Cognitive Impairment; CANS-MCl: Computer-assisted Neuropsychological Screening for MCl; CANTAB mobile: Cambridge Neuropsychological Test Automated Battery Mobile; CANTAB-

PAL: Cambridge Neuropsychological Test Automated Battery-Paired Associate Learning: CDT: Clock Drawing Test; CONCOG: Concise Cognitive Test: COST: Cognitive State Test; CST: The computerized self-test; FOME: Fuld Object-Memory Evaluation; K-L test: King-Devick test; LASSI-L: LoewensteinAcevedo Scale for Semantic Interference and Learning; M-ACE: Min Addenbrooke's Cognitive Examination; MCI screen: Mild cognitive impairment screen; MCl: Mild cognitive impairment; MES: Memory and Executive Screening; Mini-KSCAr: Mini Kingston Standardized Cognitive Assessment revised; MIS: Memory Impairment Screen; MMSE: Mini-Mental State Examination; MoCA: Montreal Cognitive Assessment; MoCA-B: Montreal Cognitive Assessment Basic; NCGG-FAT: National Center for Geriatrics and Gerontology functional assessment tool; NUCOG: Neuropsychiatry Unit Cognitive Assessment Tool; Qmci: Quick Mild Cognitive Impairment screen; RCS: Rapid Cognitive Screen; R-QCST: Revised Quick Cognitive Screening Test; RUDAS: Rowland Universal Dementia Assessment Scale; SCEB: Short Cognitive Evaluation Battery; SF-MoCA: Short-form Montreal Cognitive Assessment; SIS: Six-item screener; SKT: Short Cognitive Performance Test (Syndrom Kurztest); SLUMS: Saint Louis University Mental Status examination; sn : Sensitivity; sp: Specificity; SPMT: Scenery Picture Memory Test (SPMT); STMS: Short Test of Mental Status; TE4D-cog: Cognitive tests of the Test for the Early Detection of Dementia from Depression

\section{Acknowledgements}

The authors kindly thank all the authors from the different research studies about cognitive screening tests that shared there articles upon request.

\section{Funding}

- Uitgegeven met steun van de Universitaire Stichting van België.

- Flemish government Agency for Innovation by Science and Technology (VLAIO), embedded in the Strategic Basic Research [grant number IWT140027-SBO].

- University of Antwerp Research Fund; the Institute Born-Bunge (IBB, www.bornbunge.be)

\section{Availability of data and materials}

The datasets used and/or analyzed during the current study are available from the corresponding author on reasonable request.

\section{Authors' contributions}

EEDR conducted the literature search, processed the findings, and wrote the manuscript. PPDD, ED, and SE all contributed to the study's design and supervised the analysis and interpretation of the findings and writing of this manuscript. All authors read and approved the final manuscript.

\section{Ethics approval and consent to participate}

Not applicable.

\section{Consent for publication}

Not applicable.

\section{Competing interests}

We (the authors) declare that we have not entered into an agreement with the funding organizations that has limited our abilities to complete the research as planned and publish the results. The authors declare that they have no competing interests.

\section{Publisher's Note}

Springer Nature remains neutral with regard to jurisdictional claims in published maps and institutional affiliations.

\section{Author details}

${ }^{1}$ Department of Clinical and Lifespan Psychology, Vrije Universiteit Brussel, Brussels, Belgium. 'Laboratory of Neurochemistry and Behavior, Institute Born-Bunge, University of Antwerp, Antwerp, Belgium. ${ }^{3}$ Department of Neurology and Center for Neurosciences, UZ Brussel and Vrije Universiteit Brussel, Brussels, Belgium.

Published online: 28 February 2019

\section{References}

1. Albert MS, DeKosky ST, Dickson D, Dubois B, Feldman HH, Fox NC, et al. The diagnosis of mild cognitive impairment due to Alzheimer's disease: recommendations from the National Institute on Aging- Alzheimer's Association workgroups on diagnostic guidelines for Alzheimer's disease. Alzheimers Dement. 2011;7(3):270-9.

2. Sperling R, Aisen PS, Beckett $L$, Bennett D, Craft S, Fagan AM, et al. Toward defining the preclinical stages of Alzheimer's disease: recommendations from the National Institute on Aging and the Alzheimer's Association workgroup. Alzheimers Dement. 2011;7(3):280-92.

3. Jack CR, Bennett DA, Blennow K, Carrillo MC, Dunn B, Haeberlein SB, et al. NIA-AA research framework: toward a biological definition of Alzheimer's disease. Alzheimers Dement. 2018;14(4):535-62.

4. De Roeck EE, Engelborghs S, Dierckx E. Next generation brain health depends on early Alzheimer disease diagnosis: from a timely diagnosis to future population screening. J Am Med Dir Assoc. 2016;17:452-3.

5. Folstein MF, Folstein SE, McHugh PR. Mini-mental state: a practical method for grading the cognitive state of patients for the clinician. J Psychiatr Res. 1975;12:189-98.

6. Mitchell AJ. A meta-analysis of the accuracy of the mini-mental state examination in the detection of dementia and mild cognitive impairment. J Psychiatr Res. 2009;43:411-31.

7. Carnero-Pardo C. Should the mini-mental state examination be retired? Neurologia. 2013;29:473-81.

8. Nieuwenhuis-Mark R. The death knoll for the MMSE: has it outlived its purpose? J Geriatr Psychiatry Neurol. 2010;23(3):151-7.

9. Cullen B, O'Neill B, Evans JJ. A review of screening tests for cognitive impairment. J Neurol Neurosurg Psychiatry. 2007;78:790-9.

10. Petersen RC, Smith GE, Waring SC, Ivnik RJ, Tangalos EG, Kokmen EM. Mild cognitive impairment - clinical characterization and outcome. Arch Neurol. 1999;56:303-8.

11. Winblad B, Palmer K, Kivipelto M, Jelic V, Fratiglioni L, Wahlund LO, et al Mild cognitive impairment-beyond controversies, towards a consensus: report of the International Working Group on Mild Cognitive Impairment. J Intern Med. 2004;256:240-6.

12. American Psychiatric Association. Diagnostic and statistical manual of mental disorders (4th ed.). Washington, DC: American Psychiatric Association; 1994

13. Desgranges B, Baron J-C, Giffard B, Chételat G, Lalevée C, Viader F, et al. The neural basis of intrusions in free recall and cued recall: a PET study in Alzheimer's disease. Neuroimage. 2002;17(3):1658-64. 
14. Bäckman L, Jones S, Berger A-K, Laukka EJ, Small BJ. Cognitive impairment in preclinical Alzheimer's disease: a meta-analysis. Neuropsychology. 2005; 19(4):520-31.

15. Ehreke L, Luppa M, König H-H, Riedel-Heller SG. Is the clock drawing test a screening tool for the diagnosis of mild cognitive impairment? A systematic review. Int Psychogeriatr. 2010;22:56-63.

16. Arthanat $\mathrm{S}$, Vroman KG, Lysack C. "Who over 65 is online?" older adults' dispositions toward information communication technology. Comput Hum Behav. 2015;43:156-66

17. Hill R, Betts LR, Gardner SE. Older adults' experiences and perceptions of digital technology: (dis)empowerment, wellbeing, and inclusion. Comput Hum Behav. 2015:48:415-23.

18. Perla W, Korczyn AD. Willingness to use computerized systems for the diagnosis of dementia: testing a theoretical model in an Israeli sample. Alzheimer Dis Assoc Disord. 2012;26(2):171-8.

19. Julayanont $P$, Tangwongchai $S$, Hemrungrojn S, Tunvirachaisakul C, Phanthumchinda K, Hongsawat J, et al. The Montreal Cognitive Assessment - basic: a screening tool for mild cognitive impairment in illiterate and low-educated elderly adults. J Am Geriatr Soc. 2015;63(12): 2550-4

20. Standish TI, Molloy DW, Cunje A, Lewis DL. The ABCS 135 short cognitive screen and its subtests discriminate between normal cognition, mild cognitive impairment and dementia? Int J Geriatr Psychiatry. 2007;22:189-94.

21. Brodaty H, Low LF, Gibson L, et al. What is the best dementia screening instrument for general practitioners to use? Am J Geriatr Psychiatry. 2006;14: 391-400.

22. Lin VYW, Chung J, Callahan BL, Smith L, Gritters N, Chen JM, et al. Development of cognitive screening test for the severely hearing impaired: hearing-impaired MoCA. Laryngoscope. 2017;127:S4-11.

23. Guo Q, Zhou B, Zhao Q, Wang B, Hong Z. Memory and Executive Screening (MES): a brief cognitive test for detecting mild cognitive impairment. BMC Neurol. 2012;12:119.

24. Wiig EH, Nielsen NP, Minthon L, et al. Alzheimer's quick test: assessment of parietal function. San Antonio: Harcourt Assessment; 2002.

25. O'Caoimh R, Gao Y, Gallagher PF, Eustace J, McGlade C, Molloy DW. Which part of the Quick mild cognitive impairment screen (Qmci) discriminates between normal cognition, mild cognitive impairment and dementia? Age Ageing. 2013:42:324-30.

26. Borson S, Scanlan JM, Chen PJ, Ganguli M. The Mini-Cog as a screen for dementia: validation in a population-based sample. J Am Geriatr Soc. 2003;51:1451-4

27. Carnero-Pardo C, Espejo-Martínez B, López-Alcalde S, Espinosa-García M, Sáez-Zea C, Hernández-Torres E, et al. Diagnostic accuracy, effectiveness and cost for cognitive impairment and dementia screening of three short cognitive tests applicable to illiterates. PLoS One. 2011;6:1-6.

28. Takechi H, Dodge HH. Scenery picture memory test: a new type of quick and effective screening test to detect early stage Alzheimer's disease patients. Geriatr Gerontol Int. 2010;10:183-90.

29. Buschke H, Kuslansky G, Katz M, Stewart WF, Sliwinski MJ, Eckholdt HM, et al. Screening for dementia with the memory impairment screen. Neurology. 1999:52:231-8.

30. Malmstrom TK, Voss VB, Cruz-Oliver DM, , Cummings-Vaughn LA, Tumosa N, Grossberg GT, et al. The Rapid Cognitive Screen (RCS): a point-of-care screening for dementia and mild cognitive impairment. J Nutr Health Aging 2015; 19(7): 741-744

31. Abdel-Aziz K, Larner AJ. Six-item Cognitive Impairment Test (6CIT): pragmatic diagnostic accuracy study for dementia and $\mathrm{MCl}$. Int Psychogeriatr. 2015;27:991-7.

32. Callahan CM, Unverzagt FW, Hui SL, , Perkins AJ, Hendrie HC. Six-item screener to identify cognitive impairment among potential subjects for clinical research. Med Care 2002; 40: 771-781.

33. Apolinario D, Lichtenthaler DG, Magaldi RM, , Soares AT, Busse AL, Amaral $\mathrm{JR}$, et al. Using temporal orientation, category fluency, and word recall for detecting cognitive impairment: the 10-point cognitive screener (10-CS), Int J Geriatr Psychiatry; 2016; 31: 4-12.

34. Galetta KM, Chapman KR, Essis MD. Screening utility of the King-Devick test in mild cognitive impairment and Alzheimer disease dementia. Alzheimer Dis Assoc Disord. 2017;31(2):152-8.

35. Solomon PR, Hirschoff A, Kelly B, Relin M, Brush M, DeVeaux RD, et al. A 7 minute neurocognitive screening battery highly sensitive to Alzheimer's disease. Arch Neurol. 1998;55:349-55.
36. Mioshi E, Dawson K, Mitchell J. The Addenbrooke's cognitive examination revised (ACE-R): a brief cognitive test battery for dementia screening. Int $J$ Geriatr Psychiatry. 2006;21:1078-85.

37. Elamin M, Holloway G, Bak TH, Pal S. The utility of the Addenbrooke's cognitive examination version three in early-onset dementia. Dement Geriatr Cogn Disord. 2016:41:9-15.

38. Hsieh S, McGrory S, Leslie F, Dawson K, Ahmed S, Butler CR, et al. The miniAddenbrooke's cognitive examination: a new assessment tool for dementia. Dement Geriatr Cogn Disord. 2015;39:1-11.

39. Mansbach WE, MacDougall EE, Rosenzweig AS. The Brief Cognitive Assessment Tool (BCAT): a new test emphasizing contextual memory, executive functions, attentional capacity, and the prediction of instrumental activities of daily living. J Clin Exp Neuropsychol. 2012;34:183-94.

40. Hopkins RW, Kilik L, Day DJ, , Rows CP, Hamilton PF. The revised Kingston standardized cognitive assessment. Int J Geriatr Psychiatry, 2004; 19: 320-326.

41. Hopkins RW, Kilik L. The mini-Kingston standardized cognitive assessment. Am J Alzheimers Dis Other Demen. 2013:28:239-44.

42. Babacan-Yildiz G, Isik AT, Ur E, Aydemir E, Ertas C, Cebi MC, et al. COST: Cognitive State Test, a brief screening battery for Alzheimer disease in illiterate and literate patients. Int Psychogeriatr. 2013;25:403-12.

43. Srinivasan $\mathrm{S}$. The concise cognitive test for dementia screening: reliability and effects of demographic variables as compared to the mini mental state examination. Neurol India. 2010:58:702-7.

44. Kalbe E, Kessler J, Calabrese P, Smith R, Passmore AP, Brand M, et al. DemTect: a new, sensitive cognitive screening test to support the diagnosis of mild cognitive impairment and early dementia. Int J Geriatr Psychiatry. 2004;19:136-43.

45. Carnero-Pardo C, Gurpegui M, Sanchez-Cantalejo E, Frank A, Mola S, Barquero MS, et al. Diagnostic accuracy of the Eurotest for dementia: a naturalistic, multicenter phase II study. BMC Neurol. 2006:6:15.

46. Anderson-Hanle C, Miele AS, Dunnam M. The Fuld Object-Memory Evaluation: development and validation of an alternate form. Appl Neuropsychol. 2013;20:1-6.

47. Nasreddine ZS, Phillips NA, Bedirian V, Charbonneau S, Whitehead V, Collin I, et al. The Montreal Cognitive Assessment, MoCA: a brief screening tool for mild cognitive impairment. J Am Geriatr Soc. 2005:53:695-9.

48. Larner AJ. Short Montreal Cognitive Assessment. J Geriatr Psychiatry Neurol. 2017:30(2):104-8.

49. Walterfang M, Siu R, Velakoulis D. The NUCOG: validity and reliability of a brief cognitive screening tool in neuropsychiatric patients. Aust N Z J Psychiatry. 2006;40:995-1002.

50. Mate-Kole CC, Conway J, Catayong K, Bieu R, Sackey NA, Wood R, et al. Validation of the revised quick cognitive screening test. Arch Phys Med Rehabil. 2009;90:1469-77.

51. Storey JE, Rowland JTJ, Basic D, Conforti DA, Dickson HG. The Rowland Universal Dementia Assessment Scale (RUDAS): a multicultural cognitive assessment scale. Int Psychogeriatr. 2004;16:13-31.

52. Robert PH, Schuck S, Dubois B, Olié JP, Lépine JP, Gallarda T, et al. Screening for Alzheimer's disease with the short cognitive evaluation battery. Dement Geriatr Cogn Disord. 2003;15:92-8.

53. Flaks MK, Forlenza OV, Pereira FS, Viola LF, Yassuda MS. Short cognitive performance test: diagnostic accuracy and education bias in older Brazilian adults. Arch Clin Neuropsychol. 2009;24:301-6.

54. Tariq SH, Tumosa N, Chibnall JT. Comparison of the Saint Louis University mental status examination and the mini-mental state examination for detecting dementia and mild neurocognitive disorder — a pilot study. Am J Geriatr Psychiatry. 2006;14(11):900-10.

55. Tang-Wai D, Knopman DS, Geda YE, et al. Comparison of the short test of mental status and the mini-mental state examination in mild cognitive impairment. Arch Neurol. 2003;60:1777-81.

56. Mahoney R, Johnston K, Katona C, Maxmin K, Livingston G. The TE4D-Cog: a new test for detecting early dementia in English-speaking populations. Int J Geriatr Psychiatry. 2005;20:1172-9.

57. Crocco EA, Loewenstein DA, Curiel RE, Alperin N, Czaja SJ, Harvey PD, et al. A novel cognitive assessment paradigm to detect Pre-mild cognitive impairment (PreMCl) and the relationship to biological markers of Alzheimer's disease. J Psychiatr Res. 2018;96:33-8.

58. Maruff P, Lim Y, Darby D, Ellis KA, Pietrzak RH, Snyder PJ, et al. Clinical utility of the cogstate brief battery in identifying cognitive impairment in mild cognitive impairment and Alzheimer's disease. BMC Psychology. 2013;1. https://www.ncbi.nlm.nih.gov/pubmed/25566378. 
59. Zugouris S, Solak M. Computerized cognitive testing for older adults: a review. Am J Alzheimers Dis Other Demen. 2015;30:13-28.

60. Fowler KS, Saling MM, Conway EL, , Semple JM, Louis WJ. Paired associate performance in the early detection of DAT. J Int Neuropsychol Soc 2002; 8: 58-71.

61. Trenkle DL, Shankle WR, Azen SP. Detecting cognitive impairment in primary care: performance assessment of three screening instruments. J Alzheimers Dis. 2007;11(3):323-35.

62. Memória CM, Yassuda MS, Nakano EY, Forlenza OV. Contributions of the Computer-Administered Neuropsychological Screen for Mild Cognitive Impairment (CANS-MCI) for the diagnosis of MCl in Brazil. Int Psychogeriatr. 2014:1-9. Epub ahead of print

63. Saxton J, Morrow L, Eschman A, Archer G, Luther J, Zuccolotto A. Computer assessment of mild cognitive impairment. Postgrad Med. 2009;121:177-85.

64. Wright DW, Nevárez H, Kilgo P, LaPlaca M, Robinson A, Fowler S, et al. A novel technology to screen for cognitive impairment in the elderly. Am J Alzheimers Dis Other Demen. 2011;26(6):484-91.

65. Kluger BM, Saunders LV, Hou W, Garvan CW, Kirli S, Efros DB, et al. A brief computerized self-screen for dementia. J Clin Exp Neuropsychol. 2009;31: 234-44.

66. Dougherty JH, Cannon RL, Nicholas CR, , Hall L, Hare F, Carr E, Dougherty A, et al. The computerized self test (CST): an interactive, internet accessible cognitive screening test for dementia. J Alzheimers Dis 2010; 20: 185-195.

67. Inoue M, Jinbo D, Nakamura Y, Taniguchi M, Urakami K. Development and evaluation of a computerized test battery for Alzheimer's disease screening in community-based settings. Am J Alzheimers Dis Other Dement. 2009; 24(2):129-35.

68. Makizako H, Shimada H, Park H, Doi T, Yoshida D, Uemura K, et al. Evaluation of multidimensional neurocognitive function using a tablet personal computer: test-retest reliability and validity in community-dwelling older adults. Geriatr Gerontol Int. 2013;13:860-6.

69. Nasreddine, 2018, https://www.mocatest.org/splash/. Accessed 17 Oct 2018.

Ready to submit your research? Choose BMC and benefit from:

- fast, convenient online submission

- thorough peer review by experienced researchers in your field

- rapid publication on acceptance

- support for research data, including large and complex data types

- gold Open Access which fosters wider collaboration and increased citations

- maximum visibility for your research: over $100 \mathrm{M}$ website views per year

At $\mathrm{BMC}$, research is always in progress.

Learn more biomedcentral.com/submissions 